\title{
Spectroscopic, morphological, thermal and dielectrical analysis of composite of polythiophene with photoactive transition metal complex of W(IV)
}

\author{
SYED KAZIM MOOSVI and KOWSAR MAJID* \\ Department of Chemistry, National Institute of Technology, Srinagar 190006, India \\ *Author for correspondence (kowsarmajid@ rediffmail.com)
}

MS received 3 July 2015; accepted 27 February 2017; published online 27 September 2017

\begin{abstract}
The present work involves the synthesis of polythiophene-potassium octacyanotungstate(IV) dihydrate composite via in-situ oxidative chemical polymerization method using $\mathrm{FeCl}_{3}$ as an oxidant. The resulting composite has been subjected to Fourier transform infrared, X-ray diffraction (XRD) and scanning electron microscopy characterization techniques, which confirm the successful synthesis of the composite. XRD shows that the crystalline structure of $\mathrm{K}_{4}\left[\mathrm{~W}(\mathrm{CN})_{8}\right] \cdot 2 \mathrm{H}_{2} \mathrm{O}$ has been retained in the composite. Thermogravimetric analysis data confirm the higher thermal stability of the composite in comparison with pure polythiophene, thus allowing it to be used as a promising material for high-temperature application purposes. Dielectric studies reveal that the dielectric constant and ac-conductivity of the composite increased by several orders of magnitude as compared with pure polythiophene at all frequencies, thus showing that the material can be used for various applications in the fields of charge storage devices and high-frequency device applications, and can also serve as a potential candidate for solar cell applications.
\end{abstract}

Keywords. Polythiophene (PTh); composite; chemical synthesis; thermal study; dielectric study; ac-conductivity.

\section{Introduction}

Conducting polymers have received much attention because of their promising physical and electronic properties, besides possessing good chemical and environmental stability, which makes them tenable for many technological applications [1-3]. Conducting polymers like polyaniline (PANI), polypyrrole (PPY) and polythiophene (PTh) are well-studied polymers. Among these conducting polymers, PTh has attracted considerable interest due to its environmental stability, thermal stability, high electrical conductivity and its applications $[4,5]$. Owing to its good flexibility, ease of doping and good thermal and electrical stability, PTh has been used for various application purposes [6]. In general, conducting polymers have prompted inquisition among material scientists because of their peculiar properties of charge carrying and retention capacity. However, there are some factors like poor cyclability, poor solubility and poor retention, which restrict their long-term and critical applications. Much efforts and significant improvements have been made so far to overcome these issues. In this direction, synthesis of composites and hybrid materials has offered many solutions. Literature shows that PTh composite has been synthesized with many inorganic and organic oxides, silica, organic clays, modern materials of CNTs (SWCNTs, MWCNTs), etc. [7-12]. For example, PTh with $\mathrm{WO}_{3}$ has found application in $\mathrm{H}_{2} \mathrm{~S}, \mathrm{NO}_{2}$ and
$\mathrm{H}_{2}$ sensing [13]. $\mathrm{PTh}-\mathrm{TiO}_{2}$ composite has shown photocatalytic activities under UV light illumination [14]. Thus, with the incorporation of foreign elements, PTh composites exhibited new properties different from those of individual components. In the same direction the transition metal complex (TMC)-PTh hybrid material has also been explored by assuming that TMC is either indirectly attached or directly in a $\pi$-conjugated backbone. Many composites containing TMC and PTh have been studied and show electronic, optical and catalytic properties. A series of novel conjugated polymers containing mixed-ligand ruthenium complexes have been synthesized, characterized and investigated for their photoconductive properties [15]. PTh hybrids of transition metal bis(salicylaldeimine) have been reported, where aggregation processes are shown to occur [16]. PTh-Cobalt Salen hybrid material has been found to catalyse the reduction of $\mathrm{O}_{2}$ [17]. Therefore, from literature it is now evident that TMCs are good enough to tune the properties of conducting polymers in general and no report is available regarding composite synthesis of PTh with $\mathrm{K}_{4}\left[\mathrm{~W}(\mathrm{CN})_{8}\right] \cdot 2 \mathrm{H}_{2} \mathrm{O}$. Among TMCs, there are some that are photochemically active and have a peculiar chemistry. $\mathrm{K}_{4}\left[\mathrm{~W}(\mathrm{CN})_{8}\right] \cdot 2 \mathrm{H}_{2} \mathrm{O}$ has been chosen here for synthesis and characterization of PTh composite. The choice of $\mathrm{K}_{4}\left[\mathrm{~W}(\mathrm{CN})_{8}\right] \cdot 2 \mathrm{H}_{2} \mathrm{O}$ is because of its good photochemistry and its high thermal inertness [18]. Ultraviolet irradiation in the ligand field bands of 
octacyano-complex of tungsten(IV) causes a simple photoaquation reaction:

$$
\begin{aligned}
{\left[\mathrm{W}(\mathrm{CN})_{8}\right]^{4-}+2 \mathrm{H}_{2} \mathrm{O} \leftrightarrows } & {\left[\mathrm{W}(\mathrm{CN})_{7}\left(\mathrm{H}_{2} \mathrm{O}\right)\right]^{3-}+\mathrm{HCN} } \\
& +\mathrm{OH}^{-}
\end{aligned}
$$

The heptacyano-complex then undergoes thermal reactions, where the substitution of $\mathrm{CN}^{-}$ligands with the other ligands such as ethylenediamine, 2,2'-bipyridyl,1,10 phenanthroline and triethylenetetramine leads to the formation of stable products [19]. Considering the scope of composites involving TMCs, we here report the synthesis of composite of PTh with $\mathrm{K}_{4}\left[\mathrm{~W}(\mathrm{CN})_{8}\right] \cdot 2 \mathrm{H}_{2} \mathrm{O}$ with the objective of understanding its role in enhancing thermal and electrical properties of the composite thus achieved.

\section{Experimental}

\subsection{Chemicals}

Thiophene was supplied by Himedia (India) and was used after distillation, anhydrous ferric chloride was provided by Loba Chemicals. Sodium tungstate $\left[\mathrm{Na}_{2}\left(\mathrm{WO}_{4}\right) \cdot 2 \mathrm{H}_{2} \mathrm{O}\right]$ was supplied by Fischer Scientific. Potassium borohydride, ethanol and glacial acetic acid were supplied by Himedia (India). The reagents used were of analytical grade. All solutions were prepared in triply distilled water.

\subsection{Synthesis of $\mathrm{K}_{4}\left[\mathrm{~W}(\mathrm{CN})_{8}\right] \cdot 2 \mathrm{H}_{2} \mathrm{O}$}

Synthesis of $\mathrm{K}_{4}\left[\mathrm{~W}(\mathrm{CN})_{8}\right] \cdot 2 \mathrm{H}_{2} \mathrm{O}$ was achieved by the Leipoldt method [20]. Here, $0.05 \mathrm{~mol}$ of $\mathrm{Na}_{2}\left(\mathrm{WO}_{4}\right) \cdot 2 \mathrm{H}_{2} \mathrm{O}$ and 1.25 mol of KCN were dissolved in $90 \mathrm{ml}$ of water in a twonecked $250 \mathrm{ml}$ flask; $0.15 \mathrm{~mol}$ of freshly prepared $\mathrm{KBH}_{4}$ in $90 \mathrm{ml}$ of water was then added at room temperature with constant stirring, followed by the dropwise addition of $60 \mathrm{ml}$ of $\mathrm{CH}_{3} \mathrm{COOH}(99 \%)$ over a period of $1 \mathrm{~h}$. The reaction mixture was then heated to $90^{\circ} \mathrm{C}$ for $30 \mathrm{~min}$, cooled to room temperature and was kept for stirring overnight. In order to avoid exposure to light the flask was wrapped in aluminium foil. The mixture was then poured into $500 \mathrm{ml}$ ethanol and the resulting dark brown precipitate was then collected by filtration; 300 $\mathrm{ml}$ of boiling water was then added, followed by decolourizing charcoal and the resulting mixture was then filtered; $300 \mathrm{ml}$ ethanol was then added to the filtrate; the resulting precipitate was then washed with ethanol and ether, and was then air dried to obtain $\mathrm{K}_{4}\left[\mathrm{~W}(\mathrm{CN})_{8}\right] \cdot 2 \mathrm{H}_{2} \mathrm{O}$. The reaction involved is

$$
\begin{gathered}
4 \mathrm{WO}_{4}^{2-}+32 \mathrm{CN}^{-}+\mathrm{BH}_{4}^{-}+28 \mathrm{H}^{+} \\
\longrightarrow 4 \mathrm{~W}(\mathrm{CN})_{8}^{4-}+16 \mathrm{H}_{2} \mathrm{O}+\mathrm{B}^{3+}
\end{gathered}
$$

\subsection{Synthesis of PTh}

Thiophene $(2 \mathrm{ml})$ was taken in a titration flask containing 70 $\mathrm{ml} \mathrm{CHCl}_{3}$. To this solution, $9.0 \mathrm{~g}$ of $\mathrm{FeCl}_{3}$ dissolved in $180 \mathrm{ml}$
$\mathrm{CHCl}_{3}$ was added dropwise with constant stirring. Then the whole mixture was kept stirring for $24 \mathrm{~h}$. After 24-h stirring, the mixture was filtered; the precipitate was washed with $\mathrm{CHCl}_{3}$ and then with methanol for removing the unreacted oxidants and thiophene monomer until the solvent remained colourless. Finally this polymer material was dried in an oven at $30-40^{\circ} \mathrm{C}$ for $4-5 \mathrm{~h}$.

\subsection{Synthesis of $\mathrm{PTh}-\mathrm{K}_{4}\left[\mathrm{~W}(\mathrm{CN})_{8}\right] \cdot 2 \mathrm{H}_{2} \mathrm{O}$ composite}

The composite was synthesized by oxidative chemical polymerization using $\mathrm{FeCl}_{3}$ as an oxidant in chloroform. To the solution of $2 \mathrm{ml}$ distilled thiophene dissolved in $70 \mathrm{ml}$ of $\mathrm{CHCl}_{3}, 1.0 \mathrm{~g}$ of $\mathrm{K}_{4}\left[\mathrm{~W}(\mathrm{CN})_{8}\right] \cdot 2 \mathrm{H}_{2} \mathrm{O}$ was added with constant stirring. To this solution, $9.0 \mathrm{~g}$ of $\mathrm{FeCl}_{3}$ dissolved in 180 ml $\mathrm{CHCl}_{3}$ was added dropwise with constant stirring; 1:2 ratio was maintained between thiophene monomer and the metal complex. After 24-h stirring of the mixture, the black coloured precipitate of composite obtained was filtered and washed repeatedly with chloroform and then with methanol. The precipitate was then dried in the oven at $30-40^{\circ} \mathrm{C}$ for 4-5 h.

\subsection{Physical measurements}

Fourier transform infrared (FTIR) spectra of samples were recorded in the range of $400-4000 \mathrm{~cm}^{-1}$ using a PerkinElmer RX-1 FTIR spectrophotometer. For the FTIR spectroscopic measurements, the powder samples were mixed with spectroscopic grade potassium bromide $(\mathrm{KBr})$ in the ratio of 1:100 and were then pressed into a thin $\mathrm{KBr}$ pellet by applying a pressure of 8 tons. For the morphological analysis, scanning electron microscopy (SEM) was performed using fine powder of the as-synthesized samples on a carbon tape in a Hitachi Model S-3600N SEM. X-ray diffraction (XRD) was recorded on a PW 3050 base diffractometer with $\mathrm{Cu}-\mathrm{K} \alpha$ radiation (1.54060 ̊). Powder XRD pattern was recorded. Thermogravimetric analysis (TGA) was carried out with a universal TA Instruments V 4.5 A in an Argon atmosphere at a heating rate of $10^{\circ} \mathrm{C} \mathrm{min}{ }^{-1}$. The temperature range was from an ambient to $1000^{\circ} \mathrm{C}$. An aluminium pan was used as a reference. Dielectric study was carried out using an Agilent 4285A precision LCR meter in the range of $20 \mathrm{~Hz}-1 \mathrm{MHz}$. For this purpose, the powder was pressed into circular pellets of diameter $10 \mathrm{~mm}$ and thickness $2.4 \mathrm{~mm}$ by applying a pressure of 10 tons. Silver paint was applied on both sides of the pellet and air dried to have good ohmic contact.

\section{Results and discussion}

\subsection{FTIR characterization}

The FTIR spectra of $\mathrm{K}_{4}\left[\mathrm{~W}(\mathrm{CN})_{8}\right] \cdot 2 \mathrm{H}_{2} \mathrm{O}$, PTh and PTh$\mathrm{K}_{4}\left[\mathrm{~W}(\mathrm{CN})_{8}\right] \cdot 2 \mathrm{H}_{2} \mathrm{O}$ composite are shown in figure $1 \mathrm{a}, \mathrm{b}$ and c, respectively. The FTIR spectrum of $\mathrm{K}_{4}\left[\mathrm{~W}(\mathrm{CN})_{8}\right] \cdot 2 \mathrm{H}_{2} \mathrm{O}$ 


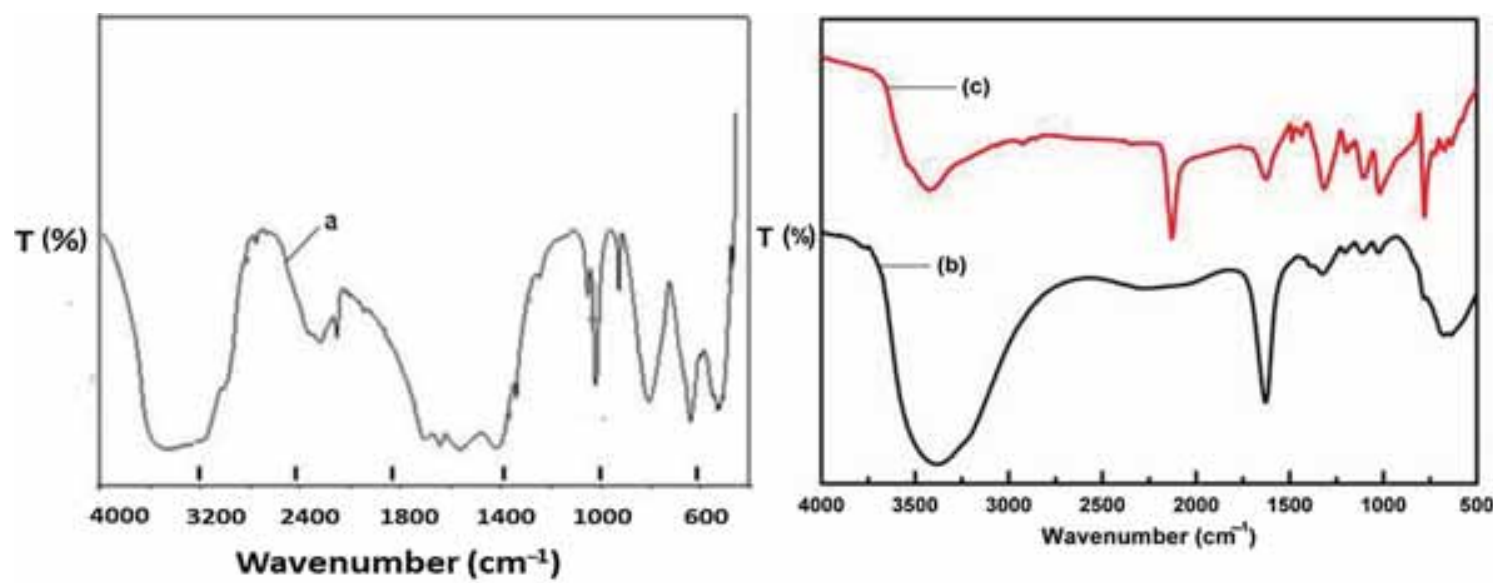

Figure 1. FTIR spectra of (a) $\mathrm{K}_{4}\left[\mathrm{~W}(\mathrm{CN})_{8}\right] \cdot 2 \mathrm{H}_{2} \mathrm{O}$, (b) $\mathrm{PTh}$ and (c) $\mathrm{PTh}-\mathrm{K}_{4}\left[\mathrm{~W}(\mathrm{CN})_{8}\right] \cdot 2 \mathrm{H}_{2} \mathrm{O}$ composite.

(figure 1a) shows an absorption peak at $3446 \mathrm{~cm}^{-1}$, which is attributed to the stretching vibration of water. The absorption peak at $1640 \mathrm{~cm}^{-1}$ due to $\delta(\mathrm{H}-\mathrm{O}-\mathrm{H})$ is also obtained. A peak at $2107 \mathrm{~cm}^{-1}$ clearly indicates the presence of cyanide group [21]. The absorption band in the lower frequency region corresponds to the $\mathrm{W}-\mathrm{CN}$ stretching vibration. The FTIR spectrum of PTh (figure 1b) exhibits characteristic vibration at $2275 \mathrm{~cm}^{-1}$ of $\mathrm{C}-\mathrm{H}$ stretching vibration band and $1628 \mathrm{~cm}^{-1}$ owing to $\mathrm{C}=\mathrm{C}$ asymmetric stretching of thiophene ring. The vibration bands observed at 1323 and $1204 \mathrm{~cm}^{-1}$ are due to $\mathrm{C}-\mathrm{H}$ bending and $\mathrm{C}=\mathrm{S}$ stretching, respectively. The bands at 1111 and $787 \mathrm{~cm}^{-1}$ represent, respectively, in-plane and out-of-plane $\mathrm{C}-\mathrm{H}$ aromatic bending vibrations of thiophene ring. Furthermore, the characteristic band of PTh at $672 \mathrm{~cm}^{-1}$ because of C-S-C ring deformation stretching is also seen in the spectrum. The band at $3392 \mathrm{~cm}^{-1}$ originated from $\mathrm{O}-\mathrm{H}$ stretching of water in the sample. Results thus obtained for IR spectrum of PTh correspond to the reported results, thus showing the successful synthesis of PTh. Figure 1c shows the FTIR spectra of PTh $-\mathrm{K}_{4}\left[\mathrm{~W}(\mathrm{CN})_{8}\right] \cdot 2 \mathrm{H}_{2} \mathrm{O}$ composite. The insertion of $\mathrm{K}_{4}\left[\mathrm{~W}(\mathrm{CN})_{8}\right] \cdot 2 \mathrm{H}_{2} \mathrm{O}$ into the PTh matrix, is evident by the presence of strong and intense peak at $2128 \mathrm{~cm}^{-1}$, which is due to $v(\mathrm{C} \equiv \mathrm{N})$. Furthermore, the intensities of some of the peaks, e.g., 3392, 1628, 1323, 1204 and $1111 \mathrm{~cm}^{-1}$, are affected by the presence of $\mathrm{K}_{4}\left[\mathrm{~W}(\mathrm{CN})_{8}\right] \cdot 2 \mathrm{H}_{2} \mathrm{O}$ during the synthesis of PTh composite. These differences in the FTIR spectra of PTh and its composite can be explained on the bases of constrained growth and restricted modes of vibration in PTh synthesized in the presence of $\mathrm{K}_{4}\left[\mathrm{~W}(\mathrm{CN})_{8}\right] \cdot 2 \mathrm{H}_{2} \mathrm{O}$. In this case, the thiophene monomer gets absorbed on the octacyanotungstate particles, which are dispersed in the reaction mixture, and the polymerization proceeds initially on the surface of particles when $\mathrm{FeCl}_{3}$ (ferric chloride) is added to the solution. This leads to adhesion of the polymer to the octacyanotungstate particles and this explains the constrained growth around these particles. As a result, the characteristic stretching frequencies are shifted towards lower frequency region $\left(1626,1316,1195,1104 \mathrm{~cm}^{-1}\right.$, etc.), as compared with pure PTh. These changes in the band's position clearly indicate the presence of weak Van der Waals force of attraction between the polymer chain and the octacyanotungstate particles [22].

\subsection{Thermal studies}

TGA of pure PTh and PTh $-\mathrm{K}_{4}\left[\mathrm{~W}(\mathrm{CN})_{8}\right] \cdot 2 \mathrm{H}_{2} \mathrm{O}$ composite is presented in figure $2 \mathrm{a}$ and $\mathrm{b}$, respectively. The thermogram of pure PTh undergoes a steep decomposition from ambient temperature to $470^{\circ} \mathrm{C}$ with a weight loss of $95 \%$. This shows a significant thermal degradation of PTh chain. In comparison with pure PTh, the thermogram of composite runs parallel up to $500^{\circ} \mathrm{C}$, at which the thermal degradation of polymer chains takes place. $\mathrm{PTh}-\mathrm{K}_{4}\left[\mathrm{~W}(\mathrm{CN})_{8}\right] \cdot 2 \mathrm{H}_{2} \mathrm{O}$ composite shows only $18 \%$ weight loss at $500^{\circ} \mathrm{C}$, whereas pure PTh shows $96 \%$ weight loss at the same temperature. These results thus confirm the high thermal stability of the composite material in comparison with pure PTh. This can be explained on the basis of Van der Waals interaction between TMC and PTh. The increase in thermal stability enables the material to be used for high-temperature application purposes.

\subsection{XRD characterization}

XRD patterns of pure PTh, potassium octacyanotungstate and $\mathrm{PTh}-\mathrm{K}_{4}\left[\mathrm{~W}(\mathrm{CN})_{8}\right] \cdot 2 \mathrm{H}_{2} \mathrm{O}$ composite are shown in figure $3 \mathrm{a}$, $\mathrm{b}$ and $\mathrm{c}$, respectively. The XRD pattern of PTh shows a broad hump at $2 \theta$ value of $20-30^{\circ}$, indicating its amorphous nature. $\mathrm{K}_{4}\left[\mathrm{~W}(\mathrm{CN})_{8}\right] \cdot 2 \mathrm{H}_{2} \mathrm{O}$ shows characteristic peaks at $2 \theta$ values of $11.69,12.97,17.19,19.28,20.50,22.70,27.03,28.30,28.41$, $29.88,32.83,33.90,35.77,36.73,41.16$ and $44.77^{\circ}$ with a relative intensity of $55.11,51.96,37.10,6.36,20.34,65.52$, $67.35,52.25,48.60,47.84,100.00,44.78,46.07,40.89,15.08$ and 28.35, respectively (table 1 ). The XRD pattern of composite of PTh with $\mathrm{K}_{4}\left[\mathrm{~W}(\mathrm{CN})_{8}\right] \cdot 2 \mathrm{H}_{2} \mathrm{O}$ shows crystalline structure by the appearance of peaks at $2 \theta$ values of 5.38 , 

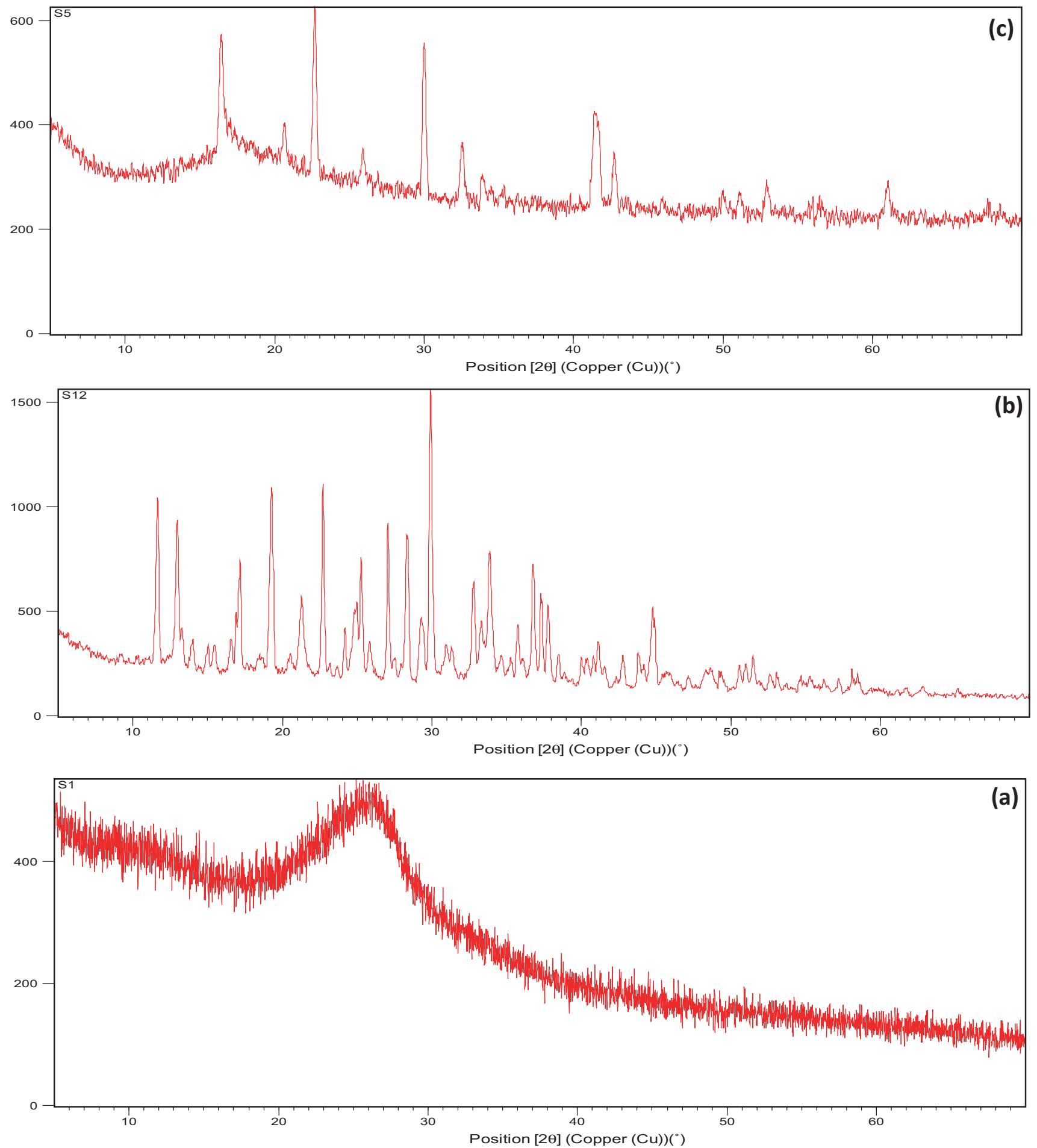

Figure 2. XRD pattern of (a) PTh, (b) $\mathrm{K}_{4}\left[\mathrm{~W}(\mathrm{CN})_{8}\right] \cdot 2 \mathrm{H}_{2} \mathrm{O}$ and (c) $\mathrm{PTh}-\mathrm{K}_{4}\left[\mathrm{~W}(\mathrm{CN})_{8}\right] \cdot 2 \mathrm{H}_{2} \mathrm{O}$ composite.

$7.20,16.40,20.65,22.68,25.91,30.06,32.59,41.33,41.73$, 42.72 and $52.96^{\circ}$ with a relative intensity of $25.87,12.69$, $71.11,23.89,100.00,19.41,82.07,32.68,54.80,44.08,32.75$ and 16.77 , respectively (table 2 ). Hence, the peaks present in the complex make their appearance in the composite, thus confirming the successful insertion of TMC into the polymer matrix. It is evident that the amorphous nature of PTh has changed into crystalline one in the nanocomposite with a number of significant peaks owing to the presence of complex. 


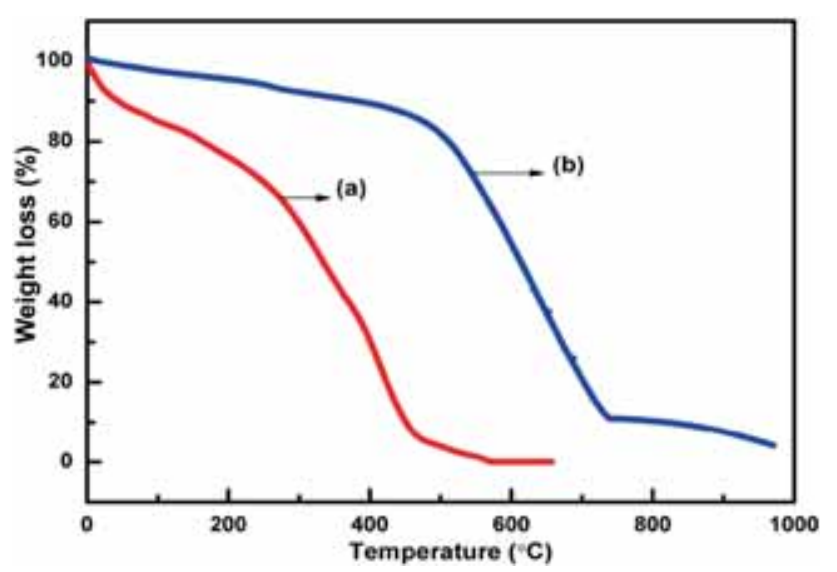

Figure 3. TGA of (a) PTh and (b) $\mathrm{PTh}-\mathrm{K}_{4}\left[\mathrm{~W}(\mathrm{CN})_{8}\right] \cdot 2 \mathrm{H}_{2} \mathrm{O}$ composite.

Table 1. XRD data of $\mathrm{K}_{4}\left[\mathrm{~W}(\mathrm{CN})_{8}\right] \cdot 2 \mathrm{H}_{2} \mathrm{O}$.

\begin{tabular}{lcccr}
\hline $\begin{array}{l}\text { Position } 2 \theta \\
(\mathrm{deg})\end{array}$ & $\begin{array}{c}\text { FWHM 2 } \theta \\
(\mathrm{deg})\end{array}$ & $\begin{array}{c}d \text {-spacing } \\
(\AA)\end{array}$ & Rel. int. $(\%)$ & $\begin{array}{r}\text { Area } \\
\text { (cts deg) }\end{array}$ \\
\hline 11.6888 & 0.1809 & 7.57104 & 55.11 & 132.20 \\
12.9680 & 0.1973 & 6.82692 & 51.96 & 135.98 \\
17.1942 & 0.0987 & 5.15728 & 37.10 & 48.55 \\
19.2768 & 0.0987 & 4.60455 & 65.52 & 85.74 \\
21.2774 & 0.0987 & 4.17591 & 26.86 & 35.14 \\
22.7053 & 0.1151 & 3.91642 & 67.35 & 102.81 \\
27.0348 & 0.1480 & 3.29825 & 52.25 & 102.56 \\
28.3020 & 0.1003 & 3.15079 & 48.60 & 87.35 \\
28.4084 & 0.0658 & 3.14183 & 47.84 & 41.73 \\
29.8808 & 0.1809 & 2.99028 & 100.00 & 239.89 \\
32.8291 & 0.0987 & 2.72816 & 34.22 & 44.78 \\
33.9029 & 0.0658 & 2.64417 & 46.07 & 40.19 \\
35.7706 & 0.1316 & 2.51028 & 20.34 & 35.48 \\
36.7258 & 0.1203 & 2.44512 & 40.89 & 88.20 \\
41.1618 & 0.2005 & 2.19128 & 15.08 & 54.19 \\
44.7736 & 0.1604 & 2.02254 & 28.35 & 81.52 \\
\hline
\end{tabular}

\subsection{SEM characterization}

SEM micrographs of PTh, $\mathrm{K}_{4}\left[\mathrm{~W}(\mathrm{CN})_{8}\right] \cdot 2 \mathrm{H}_{2} \mathrm{O}$ and $\mathrm{PTh}-$ $\mathrm{K}_{4}\left[\mathrm{~W}(\mathrm{CN})_{8}\right] \cdot 2 \mathrm{H}_{2} \mathrm{O}$ composite are shown in figure $4 \mathrm{a}$, b and $\mathrm{c}$, respectively. In figure $4 \mathrm{a}$, it is evident that pure PTh shows amorphous morphology. The SEM image of $\mathrm{K}_{4}\left[\mathrm{~W}(\mathrm{CN})_{8}\right] \cdot 2 \mathrm{H}_{2} \mathrm{O}$ (figure $4 \mathrm{~b}$ ) shows granule-like structure. Figure $4 \mathrm{c}$ shows the SEM image of $\mathrm{PTh}-\mathrm{K}_{4}\left[\mathrm{~W}(\mathrm{CN})_{8}\right] \cdot 2 \mathrm{H}_{2} \mathrm{O}$. This SEM image clearly indicates that the metal complex $\left(\mathrm{K}_{4}\left[\mathrm{~W}(\mathrm{CN})_{8}\right] \cdot 2 \mathrm{H}_{2} \mathrm{O}\right)$ is embedded in the layers of PTh matrix. The compactness of composite has increased as a result of doping. These results thus justify the successful formation of composite.

\subsection{Dielectric measurements}

Dielectric responses of chemically synthesized PTh and $\mathrm{PTh}-\mathrm{K}_{4}\left[\mathrm{~W}(\mathrm{CN})_{8}\right] \cdot 2 \mathrm{H}_{2} \mathrm{O}$ composite were measured using
Table 2. XRD data of $\mathrm{PTh}-\mathrm{K}_{4}\left[\mathrm{~W}(\mathrm{CN})_{8}\right] \cdot 2 \mathrm{H}_{2} \mathrm{O}$ composite.

\begin{tabular}{lcrrr}
\hline $\begin{array}{l}\text { Position } 2 \theta \\
(\mathrm{deg})\end{array}$ & $\begin{array}{c}\text { FWHM 2 } \theta \\
(\mathrm{deg})\end{array}$ & $\begin{array}{c}d \text {-spacing } \\
(\AA)\end{array}$ & Rel. int. (\%) & $\begin{array}{r}\text { Area } \\
(\text { cts deg) }\end{array}$ \\
\hline 5.3847 & 0.7893 & 16.41219 & 25.87 & 64.05 \\
7.2018 & 0.1480 & 12.27480 & 12.69 & 5.89 \\
16.4006 & 0.1316 & 5.40499 & 71.11 & 29.34 \\
20.6498 & 0.2631 & 4.30139 & 23.89 & 19.71 \\
22.6878 & 0.1644 & 3.91941 & 100.00 & 51.58 \\
25.9168 & 0.1973 & 3.43795 & 19.41 & 12.01 \\
30.0613 & 0.1973 & 2.97273 & 82.07 & 50.80 \\
32.5895 & 0.2631 & 2.74766 & 32.68 & 26.97 \\
41.3381 & 0.1151 & 2.18414 & 54.80 & 19.79 \\
41.7376 & 0.1316 & 2.16416 & 44.08 & 18.19 \\
42.7249 & 0.2631 & 2.11641 & 32.75 & 27.02 \\
52.9610 & 0.2631 & 1.72897 & 16.77 & 13.84 \\
61.0023 & 0.2406 & 1.51766 & 21.32 & 21.75 \\
\hline
\end{tabular}

an Agilent 4285A precision LCR meter as a function of frequency of the applied ac-field in the range of $20 \mathrm{~Hz}-1$ MHz. Figure 5 shows variations of permittivity (both $\varepsilon^{\prime}$ (real part) and $\varepsilon^{\prime \prime}$ (imaginary part)), dielectric loss $(\tan \delta$ ) and acconductivity $\left(\sigma_{\mathrm{ac}}\right)$ with the frequency of applied electric field. Following relations have been used to calculate these parameters:

$$
\begin{aligned}
\varepsilon^{\prime} & =C_{\mathrm{p}} d / \varepsilon^{\mathrm{o}} \mathrm{A}, \\
\varepsilon^{\prime \prime} & =\varepsilon^{\prime} \tan \delta, \\
\sigma_{\mathrm{ac}} & =2 \pi \nu \varepsilon^{\prime \prime},
\end{aligned}
$$

where $C_{\mathrm{p}}$ is the capacitance, $d$ is the thickness of sample, $\varepsilon^{\mathrm{o}}$ is the permittivity of the free space $\left(\varepsilon^{\mathrm{o}}=8.854 \times 10^{-12} \mathrm{~F} \mathrm{~m}^{-1}\right)$ and $A$ is the effective area.

Figure $5 \mathrm{a}$ and $\mathrm{b}$ shows the variation of real part of dielectric constant of $\mathrm{PTh}$ and $\mathrm{PTh}-\mathrm{K}_{4}\left[\mathrm{~W}(\mathrm{CN})_{8}\right] \cdot 2 \mathrm{H}_{2} \mathrm{O}$ composite with the frequency of applied electric field, respectively. It is evident from the graph that dielectric constant shows a normal dispersion behaviour. The imaginary part of dielectric constant of PTh and composite also shows a similar behaviour as shown in figure $5 \mathrm{c}$ and $\mathrm{d}$, respectively. The dielectric constant shows gradual decrease in the low-frequency region as the dipoles follow the applied field rapidly. The decreasing trend seems not too sharp in the high frequency range $\left(10^{5}-10^{6} \mathrm{~Hz}\right)$. This can be explained by dipole orientation; it is difficult to rotate the dipoles in the higher frequency range; as a result, their contribution to the polarization is negligible; hence, dielectric permittivity shows almost-frequency-independent behaviour in higher frequency range [23]. The dielectric constant $\left(\varepsilon^{\prime}\right)$ of $\mathrm{PTh}-\mathrm{K}_{4}\left[\mathrm{~W}(\mathrm{CN})_{8}\right] \cdot 2 \mathrm{H}_{2} \mathrm{O}$ composite was found to be higher than that of pure PTh. For instance, the value of dielectric constant of PTh (figure $5 \mathrm{a}$ ) and $\mathrm{PTh}-\mathrm{K}_{4}\left[\mathrm{~W}(\mathrm{CN})_{8}\right]$. $2 \mathrm{H}_{2} \mathrm{O}$ at $10^{4} \mathrm{~Hz}$ was found to be $3.5 \times 10^{2}$ and $3 \times 10^{5}$, respectively. This enhanced dielectric constant of composite can be attributed to the interfacial polarization due to 

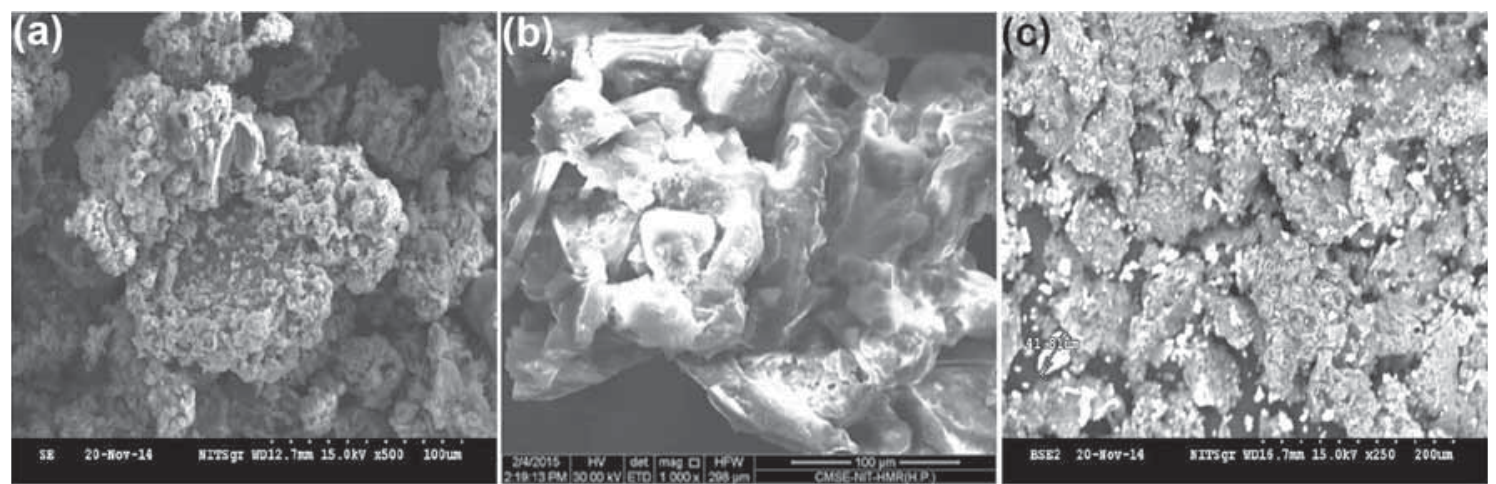

Figure 4. SEM micrographs of (a) PTh, (b) $\mathrm{K}_{4}\left[\mathrm{~W}(\mathrm{CN})_{8}\right] \cdot 2 \mathrm{H}_{2} \mathrm{O}$ and (c) $\mathrm{PTh}-\mathrm{K}_{4}\left[\mathrm{~W}(\mathrm{CN})_{8}\right] \cdot 2 \mathrm{H}_{2} \mathrm{O}$ composite.
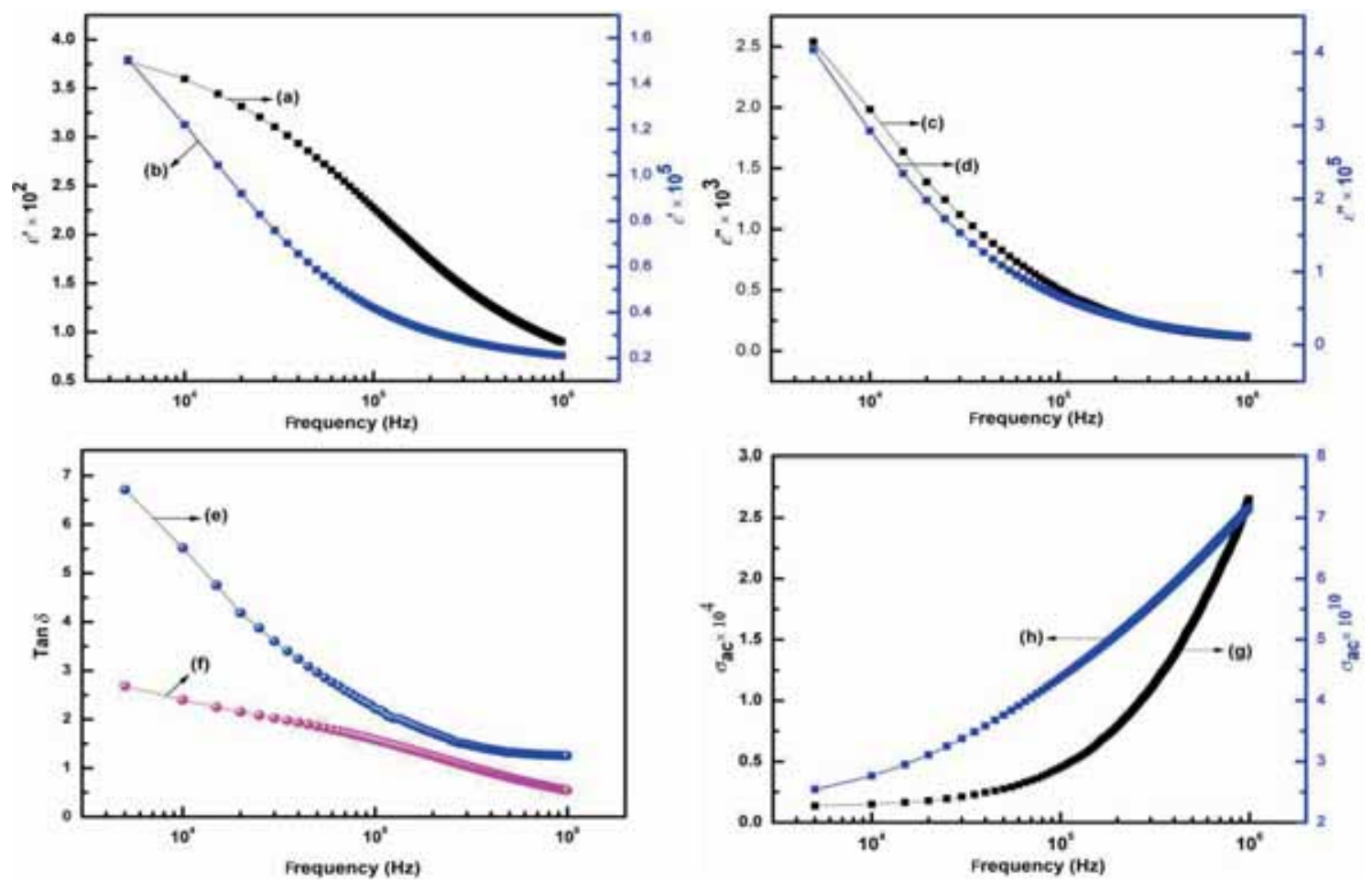

Figure 5. Variation of real permittivity of (a) $\mathrm{PTh}$ and (b) $\mathrm{PTh}-\mathrm{K}_{4}\left[\mathrm{~W}(\mathrm{CN})_{8}\right] \cdot 2 \mathrm{H}_{2} \mathrm{O}$ composite, imaginary permittivity of (c) PTh and (d) PTh $-\mathrm{K}_{4}\left[\mathrm{~W}(\mathrm{CN})_{8}\right] \cdot 2 \mathrm{H}_{2} \mathrm{O}$ composite, tangential dielectric loss of (e) PTh and (f) PTh $-\mathrm{K}_{4}\left[\mathrm{~W}(\mathrm{CN})_{8}\right]$. $2 \mathrm{H}_{2} \mathrm{O}$ composite and ac-conductivity of $(\mathrm{g}) \mathrm{PTh}$ and $(\mathrm{h}) \mathrm{PTh}-\mathrm{K}_{4}\left[\mathrm{~W}(\mathrm{CN})_{8}\right] \cdot 2 \mathrm{H}_{2} \mathrm{O}$ composite.

the presence of $\mathrm{K}_{4}\left[\mathrm{~W}(\mathrm{CN})_{8}\right] \cdot 2 \mathrm{H}_{2} \mathrm{O}$ in the PTh matrix [24]. Increase in interfacial polarization is attributed to the heterogeneous nature of composite, where two phases differ from each other in dielectric constant and conductivity. Since the conductivity of the polymer matrix and that of dopant differ, the movement of charge carriers occurs more readily and randomly through one phase, and therefore it is constricted at phase boundaries. Finally, interfacial polarization results in an increase in the permittivity due to the random mobility of charge carriers, which get trapped at the interface of a multiphase material with different conductivities (MaxwellWagner polarizations). The high value of dielectric constant of the composite enables it to be used for charge storage purposes. The variation of dielectric loss tangent as a function of frequency for PTh and $\mathrm{PTh}-\mathrm{K}_{4}\left[\mathrm{~W}(\mathrm{CN})_{8}\right] \cdot 2 \mathrm{H}_{2} \mathrm{O}$ composite is shown in figure $5 e$ and f, respectively. It is clear from the graph that the dielectric loss tangent decreases with increase in frequency, which is the normal trend. The dielectric loss gives the loss of energy from the applied field into the sample. At higher frequencies the composite shows almost zero dielectric loss; thus, it can be used for high-frequency device applications.

Figure $5 \mathrm{~g}$ and $\mathrm{h}$ shows the variation of ac-conductivity of pure $\mathrm{PTh}$ and $\mathrm{PTh}-\mathrm{K}_{4}\left[\mathrm{~W}(\mathrm{CN})_{8}\right] \cdot 2 \mathrm{H}_{2} \mathrm{O}$ composite with 


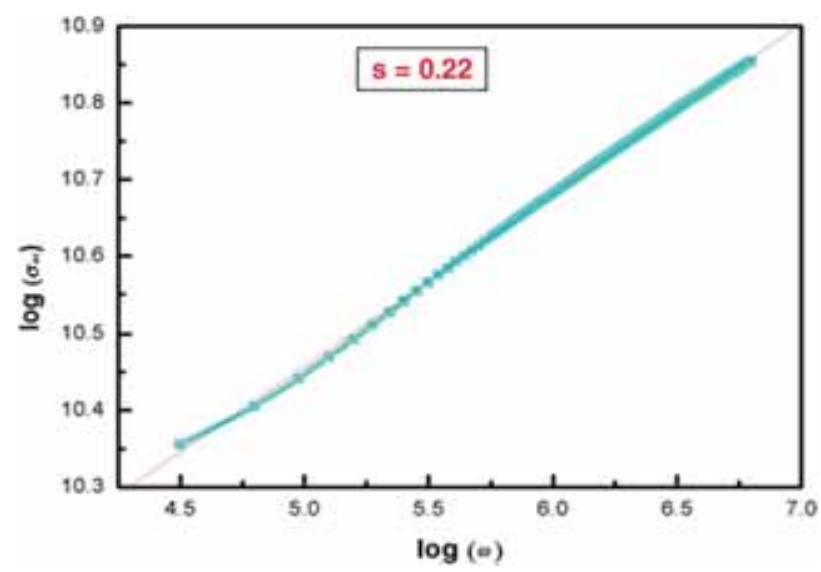

Figure 6. Plot of $\log \sigma_{\mathrm{ac}} v s . \log \omega$.

the frequency of the applied electric field, respectively. The ac-conductivity of both PTh and composite was found to increase with increase in frequency, as is evident from the graph. This frequency-dependent-behaviour of ac-conductivity can be explained on the bases of interface charge polarization (Maxwell-Wagner-Sillars effect). The composite shows higher value of ac-conductivity than that of pure PTh. The ac-conductivities of pure PTh and composite at $10^{5} \mathrm{~Hz}$ were found to be $0.4 \times 10^{4}$ and $4.3 \times 10^{10} \mathrm{~S} \mathrm{~m}^{-1}$, respectively. The higher value of ac-conductivity of composite is due to the effective dispersion of dopant in the PTh matrix (shown in SEM images), which might encourage the formation of a more efficient network for charge transport in the PTh matrix, resulting in higher conductivities [25].

The conductivity obeys the empirical law [26] for frequency dependence and is given by the relation of the form

$$
\sigma_{\mathrm{ac}}(w, \mathrm{~T})=A(T) W^{s},
$$

where $A(T)$ is a constant, generally, dependent on temperature and ' $s$ ' is the frequency exponent and generally lies in the range $0 \leq s \geq 1$. The frequency exponent ' $s$ ' can be calculated by plotting $\ln \sigma_{\mathrm{ac}} v s . \ln W$ as shown in figure 6 , whose slope is equal to the exponent ' $s$ ' and intercept is $\ln A$. The value of $s$ lies in the range $0-1$. When $s=0$, the electrical conduction is independent of frequency, which is dc conduction, but for $s \leq 1$ the conduction is frequency dependent, which is ac-conduction [27]. In the present study the value of $s$ is 0.22 for the composite, thus fitting the bill that the conduction phenomenon in the studied sample is ac-conduction, attributed to hopping of charges. This increase in conductivity of polymer by incorporating complex can be used for solar cell applications.

\section{Conclusion}

From this study, it is clear that we have synthesized a new composite of $\mathrm{PTh}$ and $\mathrm{K}_{4}\left[\mathrm{~W}(\mathrm{CN})_{8}\right] \cdot 2 \mathrm{H}_{2} \mathrm{O}$ by the in-situ oxidative chemical polymerization method. Successful synthesis of composite is evident from FTIR, XRD and SEM characterization techniques. The composite shows improved thermal stability as compared with pure PTh, which opens the gate for the material to be used for high-temperature application purposes. Dielectric study shows that the presence of $\mathrm{K}_{4}\left[\mathrm{~W}(\mathrm{CN})_{8}\right] \cdot 2 \mathrm{H}_{2} \mathrm{O}$ enhances the dielectric constant and acconductivity of the material by several orders of magnitude as compared with pure PTh in the entire frequency range. The large value of dielectric constant of the composite allows it to be used as a promising material for the applications in the fields of high-frequency device application and charge storage devices. Further, the increase in electrical ac-conductivity of polymer by incorporating $\mathrm{K}_{4}\left[\mathrm{~W}(\mathrm{CN})_{8}\right] \cdot 2 \mathrm{H}_{2} \mathrm{O}$ can be used for solar cell applications.

\section{Acknowledgements}

We are thankful to SAIF Chandigarh, SAIF STIC Kochi and NIT Hamirpur for providing the instrumentation facilities. Support and help from Dr Tabassum Ara, Head, Department of Chemistry, is also acknowledged. Syed Kazim Moosvi is also thankful to Ministry of Human Resource Development (MHRD), New Delhi, India, for providing fellowship.

\section{References}

[1] Kondawar S B, Dahegaonkar A D, Tabhane V A and Nandanwar D V 2014 Adv. Mater. Lett. 5360

[2] Wei S, Mavinakuli P, Wang Q, Chen D, Asapu R, Mao Y and Guo Z 2011 J. Electrochem. Soc. 158205

[3] Georgakilas V, Dallas P, Niarchos D, Boukos N and Trapalis C 2009 Synth. Met. 159632

[4] Palacios J C, Olayo M G and Cruz G J 2013 Open J. Polym. Chem. 334

[5] Philip B, Xie J, Chandrasekhar A, Abraham J and Varadan V K 2004 Smart Mater. Struct. 13295

[6] Karim M R, Yeum J H, Lee M S and Lim K T 2008 Mater. Chem. Phys. 112779

[7] Amarnath C A, Ghamouss F, Schmaltz B, Autret-Lambert C, Roger S, Gervais F et al 2013 Synth. Met. 16718

[8] Luo Q, Li X, Wang D, Wang Y and An J 2011 J. Mater. Sci. 461646

[9] Nawani P, Desai P, Lundwall M, Gelfer M Y, Hsiao B S, Rafailovich M et al 2007 Polymer 48827

[10] Sahoo N G, Rana S, Cho J W, Li L and Chan S H 2010 Prog. Polym. Sci. 35837

[11] Ma P C, Siddiqui N A, Marom G and Kim J K 2010 Composites Part A $\mathbf{4 1} 1345$

[12] Kiani G, Sheikhloie H and Rostami A 2011 Iran Polym. J. 206 23

[13] Guo X Z, Kang Y F, Yang T L and Wang S R 2012 Trans. Nonferrous Met. Soc. China 22380

[14] Zhu Y, Xu S, Jiang L, Pan K and Dan Y 2008 React. Funct. Polym. 681492

[15] Tsocheva D and Terlemezyan L 2005 J. Therm. Anal. Calorim. 813 
[16] Kingsborough R P and Swager T M 1998 J. Adv. Mater. 101100

[17] Kingsborough R P and Swager T M 2000 Chem. Mater. 12872

[18] Ali S I and Majid K 1998 Thermochim. Acta 311173

[19] Ali S I and Majid K 1998 Thermochim. Acta 317183

[20] Leipoldt J G, Bok L D C and Cilliers P J 1974 Z. Anorg. Allg. Chem. 407350

[21] Parish R V, Simms P G, Wells M A and Woodward L A 1968 J. Chem. Soc. A 2882

[22] Patil S D, Raghavendra S C, Revansiddappa M, Narsimha P and Prasad M A 2007 Bull. Mater. Sci. 3089
[23] Tiwari D C, Sen V and Sharma R 2012 Indian J. Pure Appl. Phys. 5049

[24] Moosvi S K, Majid K and Ara T 2016 J. Mater. Sci. Mater. Electron. 276891

[25] Moosvi S K, Majid K and Ara T 2016 Chem. Phys. 478 110

[26] Mollah S, Som K K, Bose K and Chaudhuri B K 1993 J. Appl. Phys. 74931

[27] Dar M A, Batoo K M, Verma V, Siddiqui W A and Kotnala R K 2010 J. Alloys Compd. 493553 